\title{
Retos en el diagnóstico y control del virus de la enfermedad de Marek en Colombia
}

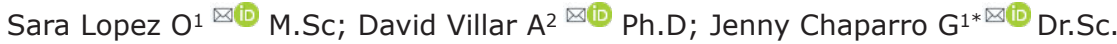 \\ ${ }^{1}$ Universidad de Antioquia. Facultad de Ciencias Agrarias. Escuela de Medicina Veterinaria. Grupo de Investigación \\ Centauro. Medellín, Colombia. \\ universidad de Antioquia. Facultad de Ciencias Agrarias. Escuela de Medicina Veterinaria. Grupo de investigación \\ CIBAV. Medellín, Colombia. \\ *Correspondence: jenny.chaparro@udea.edu.co
}

Recibido: Mayo 2018; Aceptado: Octubre 2018; Publicado: Marzo 2019.

\section{RESUMEN}

Aunque la industria avícola colombiana ha crecido casi el doble en producción durante la última década, el diagnóstico de agentes infecciosos y caracterización de estos aún es escasa, y es poca la información acerca de las cepas virales circulantes en el país. Dentro de estos agentes se encuentra el Virus de la Enfermedad de Marek (VEM), el cual es un patógeno inmunosupresor que puede causar mortalidad elevada y graves pérdidas en la producción. Aunque es poco probable que ocurran casos clínicos de la enfermedad causada por el VEM, debido a los programas de vacunación generalizada con GaHV-2 (serotipo I) y HVT (serotipo III), la inmunosupresión que causan las infecciones subclínicas puede estar causando pérdidas considerables en la producción avícola nacional. El objetivo de esta revisión es describir brevemente la enfermedad de Marek y el estado actual del estudio de la infección en Colombia.

Palabras clave: Gallid herpesvirus 1, herpesvirus, Mardivirus, inmunodepresión, virus paralítico de las aves (Fuente: MeSh).

\begin{abstract}
Although the Colombian poultry industry has almost doubled its production in the last decade, our ability to diagnose and characterize avian pathogens is deficient, and there is little information of the circulating viral pathogens. One of these pathogens is Marek disease virus (MDV), which is an immunosuppressive agent that can cause high mortality rates and substantial production losses. Currently, there are few documented clinical cases due to the implementation of mass vaccination programs with GaHV-2 strains (serotype I) and HVT (serotype III). However, losses in production rates are likely occurring-due to immunosuppression and subclinical infections. The objective of this review is to describe MDV and the current status of the infection in Colombia.-
\end{abstract}

Keywords: Fowl paralysis virus, gallid herpesvirus 1, herpesvirus, Mardivirus, immunodepression (Source: MeSh).

Como citar (Vancouver)

Lopez OS, Villar D, Chaparro GJ. Retos en el diagnóstico y control del virus de la enfermedad de Marek en Colombia. Rev MVZ Cordoba. 2019; 24(1):71577165. DOI: https://doi.org/10.21897/rmvz.1604 


\section{INTRODUCCIÓN}

La enfermedad de Marek (EM) es una enfermedad neuropática y linfoproliferativa que afecta pollos (Gallus domesticus) a nivel mundial. Es causada por un alfaherpesvirinae oncogénico altamente contagioso $(\underline{1}, \underline{2})$. Su organización genómica y su estructura molecular son similares al Herpesvirus simple humano (HVS) de la subfamilia Alphaherpesvirinae $(\underline{1}, \underline{3})$. Sin embargo, hay algunas características únicas que diferencian el Virus de la Enfermedad de Marek (VEM) de otros Alfaherpesvirus: establece latencia en los linfocitos (células T), está estrictamente asociado a células, codifica un oncogén (Meq) y es capaz de inducir linfomas de células T CD4 + $(\underline{3}, \underline{4})$. La enfermedad se caracteriza por la inmunosupresión, la infiltración de linfocitos infectados en nervios periféricos y órganos viscerales (hígado, riñón, bazo, gónadas, corazón y proventrículo) y, en última instancia, la formación de linfomas de células $T$ metastásicas $(\underline{5}, \underline{6})$.

Los pollos afectados y no vacunados generalmente sucumbirán a la enfermedad, lo que resultará en una alta tasa de morbilidad y mortalidad (ㄱ) . A principios de la década de 1970, el control de la enfermedad se logró con la introducción y el uso generalizado de la cepa no patógena, Meleagrid herpesvirus 1 (Herpesvirus de pavos o HVT). A lo largo de los años, surgió una disminución en la eficacia de la vacuna debido a la interferencia con los anticuerpos maternos y la aparición de nuevas cepas de campo altamente virulentas del VEM (8). Se cree que la evolución del VEM hacia una mayor patogenicidad fue causada por manejo de altas densidades, líneas genéticamente modificadas, manejo inadecuado de vacunas, intercambio de animales de reproducción y poco conocimiento de las prácticas de bioseguridad

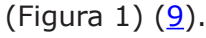

EI VEM solo puede transmitirse horizontalmente, por lo que el control de la enfermedad se puede lograr mediante la implementación de estrictos procedimientos de bioseguridad, prácticas de manejo, selección genética y programas rigurosos de vacunación $(\underline{2}, \underline{4}, \underline{5})$.

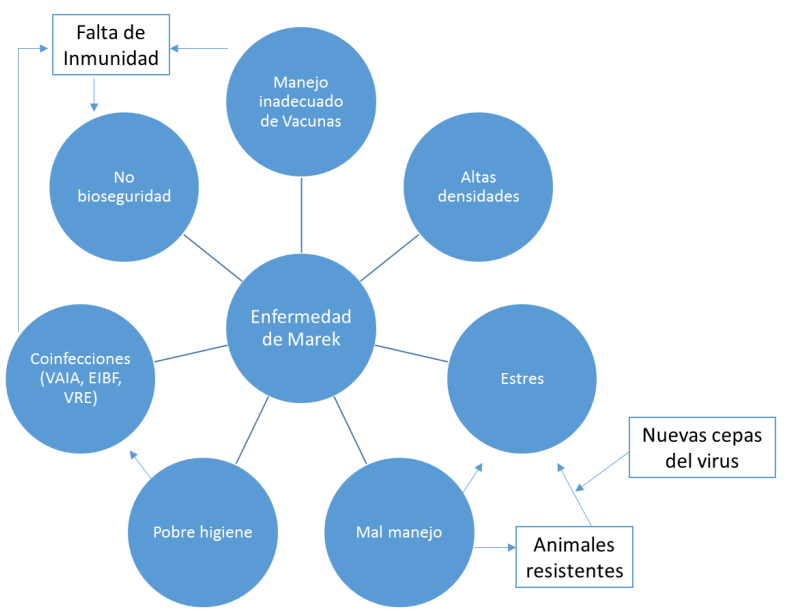

Figure 1. Red causal de la Enfermedad de Marek (EM).

Los brotes de EM por falta de inmunidad, probablemente se deben a un manejo inadecuado de las vacunas, estrés generado por la alta densidad y prácticas de manejo inadecuadas: falta de bioseguridad, falta de higiene, infección con nuevas variantes del virus ( $v v+V E M)$ y coinfección con otros virus inmunosupresores.

En el caso del VEM, los programas de control deben basarse en el conocimiento de los patotipos circulantes o cepas del virus presentes en la granja, la dinámica de la infección y la evidencia de participación en pérdidas de producción $(\underline{5}, \underline{8})$. Por lo tanto, es crucial contar con herramientas de diagnóstico capaces de caracterizar las cepas de campo circulante y monitorear la excreción del virus vacunal en el medio ambiente. Si bien existe alguna información sobre el VEM en Colombia, los datos sobre la dinámica de los virus que circulan actualmente en granjas avícolas y pollos de traspatio, así como los patotipos presentes en el campo, son escasos. Esta revisión se centrará en la situación actual de la EM en cuatro granjas colombianas, nuevas herramientas de diagnóstico disponibles en el país y algunas recomendaciones para el control en caso de presentarse enfermedad clínica.

Agente etiológico de la enfermedad de Marek. La EM es causada por un Gallid Herpesvirus 2 oncogénico (GaHV-2), también conocido como MDV-1 o serotipo 1. Los herpesvirus son virus envueltos con una cápside icosaédrica. EI VEM es específicamente un virus ADN lineal de doble cadena de aproximadamente $175 \mathrm{~kb}$ de longitud que codifica 103 proteínas (Figura 2), algunas de las cuales están asociadas con la oncogénesis ( $\underline{3}$ ). GaHV-2 está estrictamente asociado a las células en todos los órganos, excepto en el folículo de las plumas, donde los viriones infecciosos se desprenden al medio ambiente como parte de la caspa y el polvo (2). Los pollos son susceptibles a la infección por VEM, pero algunos estudios genéticos sugieren que los haplotipos específicos del complejo mayor de histocompatibilidad (MHC) pueden conferir resistencia a la progresión de la enfermedad evitando la neuropatía y la formación de linfomas (10).

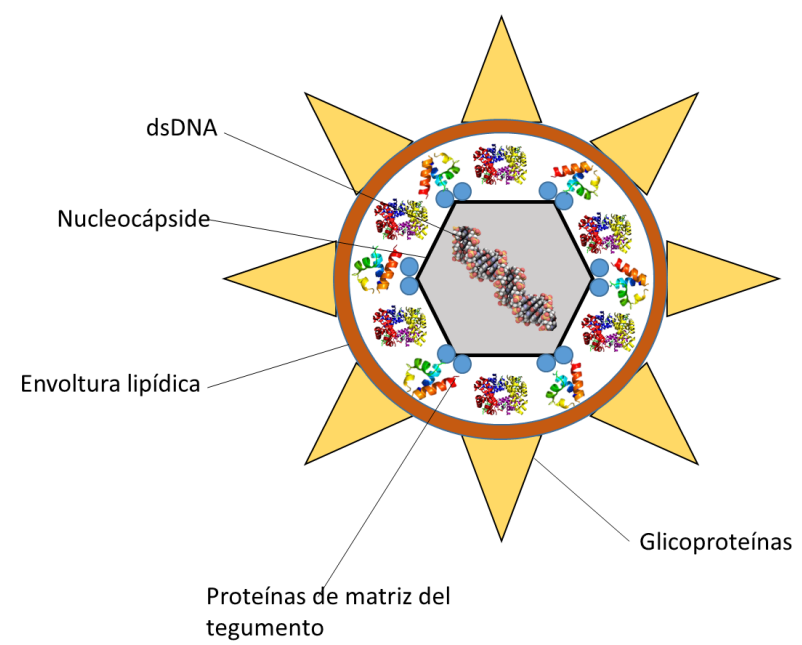

Figure 2. Representación esquemática de un alfaherpesvirus. El ADN de doble cadena lineal (dsADN) se encuentra dentro de una nucleocápside icosaédrica, que está rodeada por proteínas tegumentales (matriz proteica) y la envoltura lipídica que contiene varias glicoproteínas virales (gB, gC, gD, gE, gH, gK, gL y $\mathrm{gM})(\underline{5})$.

El primer caso de EM fue publicado en 1907 en Hungría por el Dr. Joseph Marek, por quien recibe el nombre la enfermedad. La enfermedad se reportó posteriormente en USA en 1914 y poco después en casi todos los países del mundo $(\underline{11}, \underline{12})$. Se presume que todas las aves de 
producción comercial están infectadas, sin embargo, la enfermedad clínica no siempre es evidente en las parvadas (11). En Colombia, existen reportes de EM desde 1996 (Tabla 1), pero se reconoce que la infección estaba presente antes de los años 70 . El establecimiento de medidas de control por parte del ICA (Instituto Colombiano Agropecuario) para prevenir y controlar la EM en aves de corral se decretó mediante la resolución 573 de 1973, la cual alertó sobre este problema en la industria avícola ( $\underline{13})$.

Tabla 1. Colombia / Enfermedad de Marek. Estado plurianual de la enfermedad animal. OIE 2016.

\begin{tabular}{|c|c|c|c|c|c|c|c|}
\hline \multirow[b]{2}{*}{ Año } & \multirow[b]{2}{*}{ Casos } & \multirow[b]{2}{*}{ Especie } & \multicolumn{3}{|c|}{ Número de } & \multirow[b]{2}{*}{ Mortalidad } & \multirow[b]{2}{*}{ Control } \\
\hline & & & Casos & $\begin{array}{c}\text { Aves } \\
\text { afectadas }\end{array}$ & Muertes & & \\
\hline 2013 & + & Gallina & 1 & 1000 & 470 & $47 \%$ & V \\
\hline 2012 & - & & $\ldots$ & $\ldots$ & $\cdots$ & $\ldots$ & \\
\hline 2011 & - & & $\ldots$ & $\ldots$ & $\ldots$ & $\ldots$ & \\
\hline 2010 & + & Gallina & 3 & $\ldots$ & $\cdots$ & $\ldots$ & \\
\hline 2009 & + & Gallina & 1 & $\cdots$ & $\cdots$ & $\ldots$ & \\
\hline 2008 & + & Gallina & 1 & $\ldots$ & $\ldots$ & $\ldots$ & \\
\hline 2007 & + & Gallina & 4 & $\ldots$ & $\ldots$ & $\ldots$ & \\
\hline 2006 & + & Gallina & 32 & $\ldots$ & $\cdots$ & $\ldots$ & \\
\hline 2005 & + & Gallina & 15 & $\ldots$ & $\ldots$ & $\ldots$ & $\ldots$ \\
\hline 2004 & + & Gallina & 41 & 248141 & 26259 & $10.58 \%$ & Qf V \\
\hline 2003 & + & Gallina & 43 & 246099 & 30910 & $12.56 \%$ & Qf V \\
\hline 2002 & + & Gallina & 46 & 137822 & 16416 & $11.91 \%$ & V \\
\hline 2001 & + & Gallina & 39 & 112231 & 21905 & $19.52 \%$ & $\mathrm{~V}$ \\
\hline 2000 & + & Gallina & 20 & 15407 & 3650 & $23.69 \%$ & V \\
\hline 1999 & + & Gallina & 31 & 22154 & 22154 & $100.00 \%$ & v \\
\hline 1998 & + & Gallina & 9 & 12365 & $\cdots$ & & V \\
\hline 1997 & + & Gallina & 8 & $\ldots$ & $\ldots$ & & V \\
\hline 1996 & + & Gallina & 18 & 24986 & 493 & $1.97 \%$ & * Pn V \\
\hline
\end{tabular}

Qf. Precaución en los bordes; V. Vacunación; Pn. Programa de control nacional; ... Sin información.

La evolución del VEM sugiere la aparición de cepas muy patógenas que pueden estar circulando en Colombia. La clasificación de VEM se basa en factores de virulencia y serotipos. Hay tres serotipos: el serotipo 1 (Gallid Herpesvirus 2, GaHV-2) comprende cepas patógenas y variantes atenuadas; el serotipo 2 (Gallid Herpesvirus 3. GaHV-3) es un grupo de muy baja patogenicidad, y el serotipo 3 (Meleagrid Herpesvirus 1. MeHV-1) es el Herpesvirus de los pavos (HVT), que ha sido altamente eficaz como vacuna contra la EM debido a que no es patógeno en pollos. También hay una clasificación adicional para el serotipo 1 que divide los patotipos según su virulencia: GaHV-2 leve (mMDV), GaHV-2 virulento ( $v M D V)$, GaHV-2 muy virulento ( $v$ VMDV) y muy virulento mas ( $v V+M D V)$ ). Debido a las diferentes presentaciones de la EM, existe una clasificación basada en la presentación clínica: forma visceral (tumores en las vísceras), ocular (infiltración linfoide en el iris), neural (enfermedad paralítica o neuropatía) y cutánea (tumores en la piel) $(\underline{3}, \underline{5}, \underline{14}, \underline{15})$. Sin embargo, los últimos casos reportados en Colombia y causados por GaHV-2 no desarrollaron la presentación clásica de la enfermedad y, en cambio, mostraron una alta mortalidad e infiltración linfoide en los nervios periféricos (16).
Estas cepas de GaHV-2 incluían patotipos mMDV, vMDV y vv+MDV, lo que sugiere una circulación combinada del virus vacunal y formas muy virulentas del virus de campo contra las cuales la vacuna puede no generar una protección adecuada, lo que lleva a la inmunosupresión, alta mortalidad y menor producción (información no publicada). Estos casos no documentados solo abordaron aspectos de la propagación viral, sin embargo no se determinaron los serotipos presentes, las implicaciones patológicas reales y las pérdidas de producción asociadas.

En todo el mundo, el VEM se ha vuelto más virulento durante las últimas décadas $y$, a menos que se implementen nuevas estrategias de control, es probable que se produzcan cambios en la virulencia con nuevas variantes de las cepas que actualmente estan en circulación $(\underline{9}, \underline{17})$. Hasta hace poco, las cepas colombianas de VEM solo se clasificaban según los signos clínicos, los resultados histopatológicos y los análisis filogenéticos de la proteína MEQ del VEM aislado en los brotes de la enfermedad. En estudios recientes, el árbol filogenético mostró que las cepas aisladas se agruparon con las formas muy virulentas de vvGaHV reportadas en todo el mundo $(18,19)$. Sin embargo, para confirmar que las cepas pertenecían al patotipo vv+ habría sido necesario realizar ensayos in vivo en pollos SPF (Specific Pathogen Free) (15). Tales ensayos no se han realizado en Colombia debido a la falta de producción de huevos SPF y la falta de unidades de aislamiento para mantener los pollos SPF. Esta situación ha llevado a la falta de información sobre las cepas del VEM circulantes que causan brotes de la EM en el país.

Recientemente, la identificación de los serotipos del VEM se realizó mediante PCR convencional y qPCR (17), lo que demostró que los tres serotipos estaban presentes en 4 granjas y en 10 fincas de traspatio examinadas en Antioquia, Colombia. Esta información sugiere que más de una cepa del VEM está circulando actualmente en las granjas, lo que en última instancia podría conducir a la aparición de nuevas cepas virulentas. La vacuna con la cepa Rispens (disponible en Colombia), contra el VEM ha demostrado que permite que las cepas vv+MDV se repliquen y se excreten en el ambiente a través del hospedador vacunado, lo que potencialmente permite su

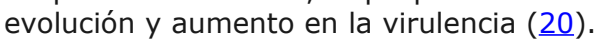

La evolución del VEM se ha realizado constantemente en los Estados Unidos y Europa. Hay varias hipótesis, aunque no confirmadas, de por qué el VEM evoluciona. La intensificación de la industria avícola (altas densidades) y la introducción de diferentes generaciones de vacunas se ha sugerido como la principal causa de la evolución. El uso de CVI988 (cepa Rispens) ha sido continua desde 1972 , sin casos aparentes de falla en la protección de las vacunas hasta 1990. Esta cepa es la única alternativa válida contra infecciones con $\mathrm{v} v+M D V$, por lo que es una preocupación para la industria avícola, si el VEM continúa su evolución y supera la protección conferida por esta vacuna $(\underline{20}, \underline{21})$. Sin embargo, es incierto si el VEM continuará su evolución hacia cepas de una mayor virulencia $(\underline{3}, \underline{8}, \underline{9})$. La HVT y las vacunas bivalentes han brindado una buena protección durante al menos 10 años, pero es probable que la eficacia de estas vacunas esté disminuyendo $(\underline{8}, \underline{9})$. Aunque la EM está bajo control en casi todo el mundo, brotes esporádicos ocurren periódicamente en algunos países con cepas vv+MDV, lo que sugiere que la protección con las vacunas usadas 
actualmente puede estar fallando ( $\underline{8})$. Estas cepas vV+MDV inducen una alta mortalidad asociada con edema cerebral en pollos no vacunados. Además, pueden causar lesiones linfoproliferativas en el cerebro que están asociadas con signos neurológicos (ㅁ).

VEM: Infección, Transmisión e Inmunosupresión. Los pollos son susceptibles a la infección por VEM. La transmisión se produce a través del tracto respiratorio, después de la inhalación de particulas infecciosas del VEM a partir del medio ambiente. La actividad fagocítica de las células del sistema inmune innato en los pulmones (macrófagos y células dendríticas), provoca la adsorción del virus y la diseminación a los órganos linfoides (bursa, timo y bazo). El receptor para el VEM en la superficie celular no se ha identificado, por lo tanto, el mecanismo molecular detrás de la entrada en la célula no está claro (8). Dos o tres días después de la infección (pi), el VEM está presente en los órganos linfoides, por lo que se establece la infección de las células del sistema inmunitario adaptativo debido a su tropismo específico por este.

La infección citolítica es particularmente evidente 5-6 días pi. El VEM tiene un tropismo específico por las células B. La necrosis de las células $B$ ocasiona el reclutamiento de células inflamatorias, como macrófagos, células $T$ y $B$ (22) al sitio específico de la lesión. Las células T activadas son un punto clave para la progresión de la infección y la patogénesis, ya que las células T en reposo y las células T naive son refractarias al VEM. Estas células T activadas permiten la replicación viral y también proporcionan el mecanismo para establecer la latencia viral $(\underline{23}, \underline{24})$. Alrededor de 7 a 8 días pi, la infección se vuelve latente y no hay evidencia de infección lítica en los órganos linfoides. En este punto, la aplicación del diagnóstico histológico proporcionaría un resultado falso negativo y se necesitarían técnicas de PCR para detectar el VEM en órganos linfoides y linfocitos de sangre periférica $(\underline{5}, \underline{8})$.

Aunque el VEM puede infectar diferentes órganos dentro de su huésped, la capa queratinizada del epitelio escamoso estratificado del folículo de plumas es el único lugar conocido donde se producen los viriones maduros. Por lo tanto, los folículos de las plumas desempeñan un papel central en la transmisión viral horizontal y la epidemiología de la $\operatorname{EM}(\underline{5}, \underline{25}, \underline{26})$. Las partículas virales infecciosas se eliminan en el medio ambiente, completan el ciclo de replicación viral y actúan como la principal fuente de infección para las aves susceptibles, a través de la inhalación de polvo o caspa (Figura 3). Hasta la fecha, no existen reportes de transmisión vertical del VEM.

Al igual que otros virus, el control de la infección por el VEM requiere la actividad coordinada de la respuesta inmune innata y la adaptativa. La interacción hospedadorpatógeno resulta en una respuesta compleja con la producción de factores solubles, como citoquinas y anticuerpos, que apoyan la función de las células del sistema inmunitario, incluidos los macrófagos, las células asesinas naturales, las células $T$ cooperadoras y los linfocitos T citotóxicos (27). Debido a que el virus está asociado estrictamente a las células linfoides, la respuesta

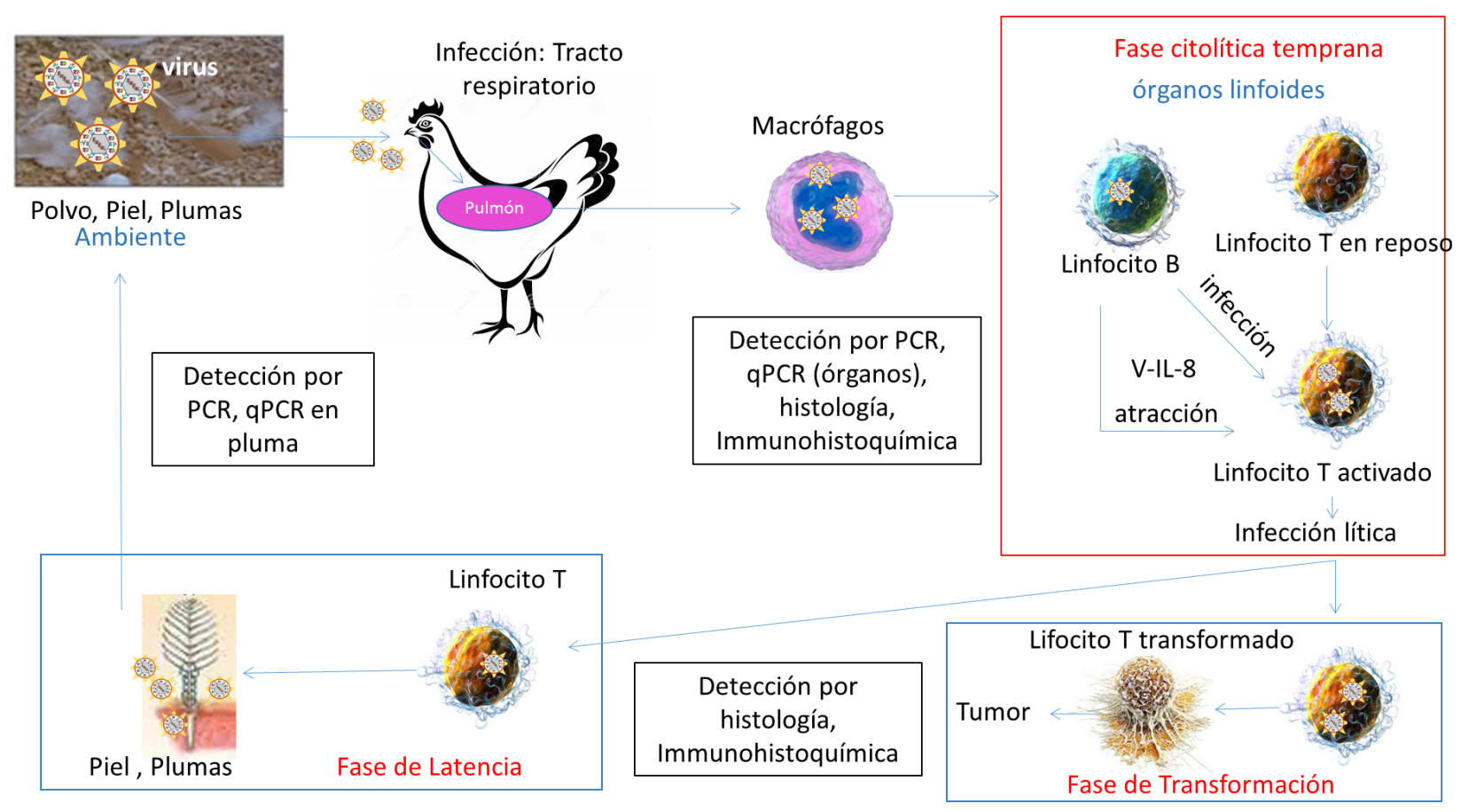

Figura 3. La entrada viral en el sistema respiratorio en las aves jóvenes marca la fase de infección inicial. Posteriormente, la replicación de partículas virales induce señales proinflamatorias que atraen macrófagos con actividad fagocítica en los pulmones. Las células infectadas migran a los órganos linfoides (bazo, timo, bursa) e infectan los linfocitos B y T activados que causan la infección lítica primaria de las células del sistema inmunitario (fase citolítica temprana). Los linfocitos T infectados entran en la fase de latencia (escape viral de la detección inmunitaria). A partir de entonces, el virus migra a la piel y se replica en el folículo de la pluma, ensamblando las partículas infecciosas que se liberarán en el polvo y la caspa. En rojo: fase de infección. La replicación viral secundaria en los linfocitos T genera otra fase de inmunosupresión y eventualmente el desarrollo de los tumores (fase de transformación). En cuadrado negro: método de detección para el diagnóstico. Adaptado de (므). 
inmune mediada por las células T desempeña un papel importante en el control de la infección; mientras que los anticuerpos solo son efectivos cuando el virus se encuentra en forma libre o cuando los antígenos del VEM se expresan en las células $(\underline{28}, \underline{29})$. Para más detalles de la respuesta inmune contra el VEM $(\underline{27}, \underline{30})$.

Herramientas de diagnóstico y situación actual en Colombia. La OIE recomienda diferentes técnicas para diagnosticar la EM. Las técnicas indirectas incluyen ELISA, AGID e IFI. Las técnicas directas incluyen histopatología, inmunohistoquímica, PCR, aislamiento de virus e inmunoprecipitación. Más recientemente, se han aplicado nuevas técnicas para la detección del VEM, como qPCR y LAMP, que son más sensibles, específicas, confiables y más rápidas $(\underline{31}, \underline{32}, \underline{33})$. Las técnicas serológicas no se recomiendan por completo debido a su poca sensibilidad en un brote de la EM. Además, no son útiles para monitorear el estado de la vacunación debido a la ausencia de anticuerpos para controlar la infección. En consecuencia, deben usarse técnicas directas en lugar de pruebas serológicas para el diagnóstico y control adecuados de la infección por el VEM.

Para identificar los serotipos específicos presentes en las granjas de pollos de engorde y ponedoras, y para monitorear el estado de vacunación, se han desarrollado herramientas moleculares que permiten una rápida cuantificación del número de copias del genoma del VEM en plumas y polvo (qPCR) $(\underline{19}, \underline{34}, \underline{35})$. El polvo se puede recolectar de los comederos y canales de agua en tubos de $15 \mathrm{~mL}$ para su posterior transporte al laboratorio en condiciones de refrigeración; las plumas deben tomarse de aves vivas e idealmente en las primeras etapas de crecimiento (Figura 4). La qPCR en plumas proporciona información específica con respecto a la propagación viral, y se puede utilizar como una herramienta para controlar la eficacia del programa de vacunación $(\underline{20}, \underline{26}, \underline{33}, \underline{35})$.

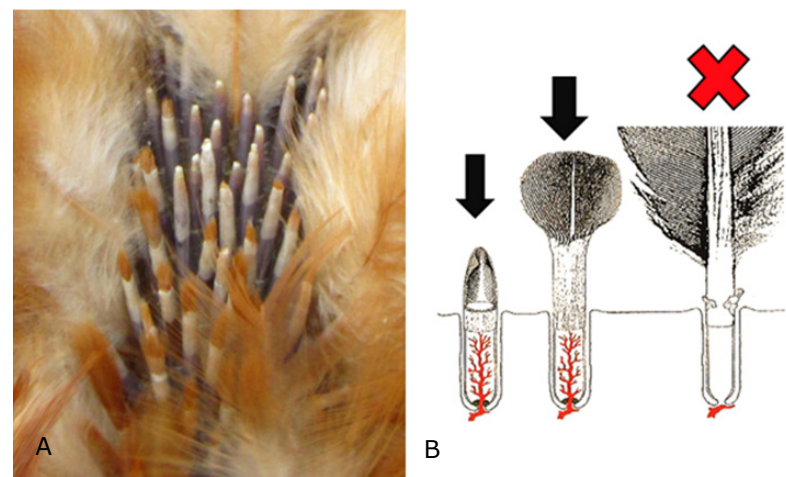

Figura 4. A. Fotografía de plumas en crecimiento en un ala. B. Diagrama que representa las diferentes etapas involucradas en el crecimiento de las plumas. Las plumas en crecimiento tienen una rica fuente de nutrientes favorecida por la presencia de capilares. Las plumas completamente desarrolladas con células foliculares en reposo carecen de este sistema. Flecha negra: la etapa correcta de la pluma para el muestreo. El mejor sitio para tomar la muestra es debajo de las alas (región axilar). Evita las plumas del ala y la cola porque es doloroso para las aves.

Se recomienda verificar la presencia del VEM en las plumas, ya que las partículas infecciosas libres de células se liberan del epitelio del folículo de la pluma 2 a 4 semanas después de la infección (es decir, las fases productivas de la infección por el VEM) y continúan eliminándose de manera intermitente durante toda la vida del ave ( $\underline{36})$. Sin embargo, se ha informado que el VEM se puede detectar en plumas tan temprano como 2 días pi (므).

Un método de qPCR para GaHV-2 ahora está disponible en Colombia (Facultad de Ciencias Agrarias, Universidad de Antioquia) y se puede realizar en cualquier tipo de muestra biológica, pero es ideal realizarlo en folículos de plumas en crecimiento. La dinámica normal del VEM en sangre y plumas de un pollo vacunado con CVI988 a 1 día de edad se muestra en algunas publicaciones $(\underline{36}, 39)$. Sin embargo, esta dinámica puede ser diferente para otros serotipos, o cuando hay coinfección con cepas vV+MDV $(\underline{37}, 38)$. La tabla 2 proporciona una lista del tipo de técnicas de diagnóstico disponibles y la muestra biológica ideal que debe enviarse para cada prueba.

Tabla 2. Técnicas de diagnóstico para MDV y órgano utilizado.

\begin{tabular}{cccc}
\hline Órgano & Histopatología & PCR y qPCR & Aislamiento \\
\hline Bazo & $\mathrm{x}$ & $\mathrm{X}$ & $\mathrm{X}$ \\
Pluma & & $\mathrm{x}$ & \\
Sangre entera & & $\mathrm{x}$ & \\
Piel & $\mathrm{x}$ & & \\
Nervios & $\mathrm{x}$ & & \\
Hígado & $\mathrm{x}$ & & $\mathrm{x}$ \\
Proventrículo & $\mathrm{x}$ & & \\
Ojo & $\mathrm{x}$ & & \\
Polvo & & $\mathrm{x}$ & \\
\hline
\end{tabular}

Los órganos para PCR, qPCR y aislamiento del virus deben enviarse refrigerados $\left(4^{\circ} \mathrm{C}\right)$ o en solución salina tamponada, empaquetados entre bloques de hielo. Para histopatología, los órganos deben fijarse en formalina al $10 \%(1: 10)$ y de no más de $5 \mathrm{~mm}$ de espesor. El polvo puede ser enviado a temperatura ambiente o refrigerado.

El aislamiento y posterior análisis de secuencias del VEM es esencial para monitorear los cambios en las cepas de campo y para la evaluación de la eficacia de la vacuna. En Colombia, hay reportes de brotes de enfermedad en poblaciones de pollos que se habían vacunado con HVT y CVI988, lo que sugiere que la inmunidad generada con la vacuna no fue protectiva contra las cepas de campo circulantes (16).

La determinación de la virulencia real de una cepa del VEM no está claramente definida. El Laboratorio de Oncología y Enfermedades Aviares de la USDA (USDAADOL) proporcionó el esquema de patotipificación del VEM basado en los IP proporcionados por el herpes virus de los pavos (HVT) y vacunas bivalentes HVT/ MDV serotipo 2 (MDV2). Este método se ha utilizado desde 1989 y se considera la prueba de oro. El protocolo para la determinación de patotipos requiere cepas de pollos específicas, 9 semanas de período experimental, unidades especiales de aislamiento para pollos infectados y no infectados y un alto nivel de bioseguridad. Pocos países pueden realizar el protocolo debido a todos los requisitos y costos involucrados en el procedimiento $(\underline{39}, \underline{40})$. Este protocolo se modificó posteriormente para facilitar su adopción $(\underline{15}, \underline{41})$. Muchos países comenzaron a usar estos nuevos protocolos, pero los procedimientos son diferentes en las cepas de virus y líneas de pollo utilizadas (42). También se han desarrollado métodos alternativos y menos costosos con ventajas y desventajas con respecto a la prueba de oro estándar $(\underline{15}, \underline{43}, \underline{44})$. 
Virus de la enfermedad de Marek en Colombia: programas de diagnóstico y control. Para que los casos de EM sean oficiales, es obligatorio enviar órganos (bazo, hígado, nervio ciático, tumores) a los laboratorios de ICA, donde las técnicas aprobadas por la OIE están disponibles, y los resultados se ingresan en la base de datos de Organización Mundial de Sanidad animal. El reporte del VEM se encuentra en la lista de enfermedades de la OIE B para el país. Sin embargo, las técnicas para caracterizar la infección y las cepas en cuestión no se realizan, y serían cruciales para establecer cualquier programa de control y medidas preventivas.

Actualmente, existen técnicas moleculares como la PCR y qPCR disponibles en la Universidad de Antioquia, que pueden detectar material genético viral y también pueden estimar el número de copias del genoma presentes en la muestra $(37,38, \underline{45})$. Se puede utilizar inmunohistoquímica (IHC) en los órganos afectados para asociar la presencia del virus con el tipo de lesiones. Además, es posible usar anticuerpos contra la proteína pp38 o Meq en la IHC para la detección de la fase lítica o de transformación del virus $(\underline{14}, \underline{46}, \underline{47})$.

Después de un brote de la EM, la recomendación es desinfectar todos los galpones con una solución antiviral y cuando los pollos terminen su ciclo, dejar un vacío sanitario durante al menos 4 semanas después de limpiar a fondo con una solución desinfectante. Las granjas deben reforzar el nivel de bioseguridad y verificar las pautas de vacunación adecuadas en la incubadora. Además, se recomienda verificar la carga viral (cepas vacunales y cepas de campo) en plumas y polvo para determinar la cantidad de virus en el ambiente.

Para controlar la enfermedad durante un brote, algunos autores recomiendan la vacunación de la parvada afectada con CVI988. Se ha demostrado que esto reduce la mortalidad y la infección en pollos sanos $(\underline{37}, \underline{38}, \underline{39}, \underline{48}, \underline{49})$. Sin embargo, dado que no existe tratamiento para la EM, debe realizarse tratamiento paleativo y es probable que la mayoría de los pollos afectados con tumores o signos nerviosos mueran tarde o temprano ( $\underline{3})$.

En 1992, el ICA publicó el programa nacional de vacunación (Resolución 811, 1992), que establecía que todos los pollos deberían vacunarse al día 1 de edad contra el VEM. Actualmente, la vacunación contra el VEM está regulada por las resoluciones del ICA No: 3649, 3651 y 3652 de 2014, que establecen los requisitos para el registro sanitario de las granjas avícolas y su certificación de bioseguridad, y también establece una vacunación obligatoria en el criadero el día 18 de incubación (in ovo) o el día 1 de edad (subcutáneo). Se supone que la vacuna contra el VEM establece una infección persistente y una buena inmunidad que puede proteger contra la neuropatía, la formación de tumores y la mortalidad. Sin embargo, debido a que las vacunas no proporcionan inmunidad completa $(\underline{8}, \underline{50})$, los pollos pueden infectarse con la vacuna y las cepas virulentas del VEM al mismo tiempo.
En Colombia, la situación epidemiológica de la EM es desconocida. Se cree que las cepas de campo del VEM están presentes en todas las granjas, debido a los informes recientes de problemas en la producción, tanto en pollos de engorde como en ponedoras, asociados con casos de inmunosupresión. En 2014, López-Osorio et al (51) estudiaron los órganos linfoides, mediante histopatología, en ponedoras en crecimiento de cuatro granjas en Antioquia y describieron una inmunosupresión de moderada a grave en aves de menos de dos meses de edad, que probablemente estaban asociadas con la presencia de virus inmunosupresores, incluyendo el VEM y el VAIA (virus de la anemia infecciosa aviar).

Los autores antes mencionados también realizaron PCR y qPCR en plumas y sangre para estudiar la infección viral y la posible diseminación del virus, y también realizaron la secuenciación del gen Meq. Se encontró que diferentes patotipos estaban circulando en las granjas (vacunal, mMDV y vMDV) y las aves tenían patrones inusuales de excreción del virus, caracterizados por picos de eliminación viral a los 30 y 60 días de edad. Recientemente, se describió un caso de EM en ponedoras infectadas con una cepa altamente patógena ( $v \mathrm{~V}+\mathrm{MDV}$ ), en la región andina, y se caracterizó por una alta tasa de mortalidad $(30 \%)$ y un infiltrado linfoide severo de los nervios (16). Algunos de los casos de infección con el VEM reportados por ICA entre 2002 y 2012 fueron confirmados posteriormente por inmunohistoquímica. En 2017, Lopera reportó que el 30,4\% (17/56) de las muestras en algunos de esos casos, diagnosticados por histopatología, fueron positivos para la proteína pp38 y no tuvieron cambios neoplásicos, lo que indica que los pollos se encontraban en la fase citolítica de la enfermedad ( $\underline{53})$.

El aislamiento y el análisis filogenético del VEM en Colombia se ha realizado en algunas aves de postura vacunadas con HVT o CVI988 (16). Sin embargo, la patogenicidad del VEM que circula en Colombia sigue sin determinarse. El aislamiento y cultivo de cepas de campo del VEM es esencial para monitorear los cambios en las cepas de campo y para la evaluación de la eficacia de la vacuna. Es esencial contar con una unidad de aislamiento para la cría de animales SPF y así realizar una patotipificación in vivo, aislando las cepa circulantes, no solo para el VEM, sino también para otros virus de aves.

En conclusión, aunque existe cierta información sobre las cepas de VEM que circulan en Colombia, se desconoce la dinámica del virus y los patotipos presentes en el campo. Debido a esta falta de información y a que los programas de control se basan simplemente en criterios comerciales, las prácticas actuales podrían incluso favorecer la aparición de formas más virulentas del virus y aumentar la susceptibilidad a otros patógenos, ya sean virales, bacterianos o parasitarios. Es necesario desarrollar técnicas que permitan la determinación de patotipos virales y realizar un monitoreo de rutina para evaluar la eficacia de la vacuna. Con esta información, los veterinarios podrán formular programas sanitarios que se adapten mejor a cada granja avícola de forma específica y establecerán un programa de vacunación más riguroso contra el VEM y otros agentes infecciosos circulantes. 


\section{REFERENCIAS}

1. Dufour-Zavala L. A Laboratory Manual for the Isolation, Identification, and Characterization of Avian Pathogens. 6th Edition, Chapter 52. Jacksonville, Fl. United States: American Association of Avian Pathologists; 2016.

2. Shahzad MK, Majeed KA, Younus M. Marek' $\mathrm{S}$ Disease: A Mini-Review. IJAVMS. 2007; 1:4-8.

3. Swayne D, JR Glisson, LR McDougald, LK Nolan, DL Suarez, VL Nair. Diseases of poultry. $13^{\text {th }}$ Edition. John Wiley \& Sons, inc; 2017. URL Available in: https://onlinelibrary.wiley.com/doi/ book/10.1002/9781119421481

4. Kato S, Horiuchi T, Mikami T, Hirai K. (Eds.) Advances in Marek's Disease Research. Osaka Japanese Association on Marek's Disease: Japon; 1988.

5. Davidson F, Nair V. (Editors). Marek disease virus: An Evolving Problem. 1ed. Compton, UK: Elsevier BV; 2004.

6. Silva RF, Cheng $H H$, Coussens $P M$, Lee LF, Velicer LF (Eds.) Current Research on Marek's Disease Kennett Square PA. United States: American Association of Avian Pathologists; 1996.

7. Cuello S, Vega A, Relova D. Enfermedad de Marek: Breve reseña bibliográfica y situación actual. Rev Electrónica Vet. 2014; 15(10):1-19. Available from: http://www.veterinaria.org/revistas/redvet/ n101014/101405.pdf

8. Gimeno IM. Marek's disease vaccines: A solution for today but a worry for tomorrow?. Vaccine. 2008; 26(8):C31-41. DOI: https://doi.org/10.1016/j. vaccine.2008.04.009

9. Nair V. Evolution of Marek's disease - A paradigm for incessant race between the pathogen and the host. Vet J. 2005; 170:175-83.

10. Ross N, Sullivan G, Coudert F. Influence of chicken genotype on protection against Marek's disease by a Herpesvirus of turkeys recombinant expressing glycoprotein B (gB) of Marek's disease virus. Vaccine. 1996; 14(3):187-189 DOI: https://doi. org/10.1016/0264-410X(95)00215-M

11. Biggs PM. The history and biology of Marek's disease virus. In: Hirai K, editor. Current Topics in Microbiology and Immunology,. Berlin: SpringerVerlag; 2001.

12. Fehler F. Marek's Disease: History, actual and future perspectives. Lohman Inf. 2001; 25:1-5. URL Available: http://lohmann-information.de/ content/I_i_25_article_4.pdf

13. Instituto Colombiano Agropecuario (ICA). RESOLUCIÓN No. 587 (Diciembre 27 de 1973) "Por la cual se dictan medidas para el control de la enfermedad de Marek en las aves de corral." [cited 2015 Feb 25]. Colombia; 1973.
14. Gimeno IM, Fletcher OJ, Montiel E, Osuna ON, Majó RD, Smyth JA, et al. Enfermedades inmunosupresoras en avicultura. Servet E: España; . 2013.

15. Witter RL, Calnek BW, Buscaglia C, Gimeno IM, Schat KA. Classification of Marek's disease viruses according to pathotype: philosophy and methodology. Avian Pathol. 2005; 34(2):75-90. DOI: http://dx.doi.org/10.1080/03079450500059255

16. Lopez-Osorio S, Piedrahita D, Espinal-Restrepo MA, Ramirez-Nieto GC, Nair V, Williams SM, et al. Molecular characterization of Marek' $s$ disease virus in a poultry layer farm from Colombia. Poult Sci. 2017; 96(6): 1598-1608. DOI: http://dx.doi. org/10.3382/ps/pew464

17. Lopez-Osorio S, Chaparro JJ, Piedrahita D, Ramírez GC. Presencia de los Virus de la Enfermedad de Marek y Anemia Infecciosa Aviar en aves de levante del norte y oriente del departamento de Antioquia [Maestría en Ciencias Veterinarias]. Colombia: Universidad de Antioquia; 2015.

18. Gong Z, Zhang L, Wang J, Chen L, Shan H, Wang $Z$, et al. Isolation and analysis of a very virulent Marek's disease virus strain in China. Virol J. 2013; 10(1):155. DOI: http://dx.doi.org/10.1186/1743422X-10-155

19. Zhang Z, Liu S, Ma C, Zhao P, Cui Z. Absolute quantification of a very virulent Marek's disease virus dynamic quantity and distributions in different tissues 1. Poult Sci. 2015; 94(6):1150-7.DOI: https://doi.org/10.3382/ps/pev063

20. Atkins $K E$, Read $A F$, Savill NJ, Renz KG, Islam AF, Walkden-Brown SW, et al. Vaccination and reduced cohort duration can drive virulence evolution: Marek's disease virus and industrialized agriculture. Evolution. 2013; 67:851-860. DOI: https://doi. org/10.1111/j.1558-5646.2012.01803.x

21. Silva RF, Cheng HH, Coussens PM, Lee LF, Velicer LF. Current Research on Marek's Disease. Kennett Square: American Association of Avian Pathologists; 1996.

22. Shek WR, Schat KA, Calnek BW. Characterization of non-oncogenic Marek's disease virus-infected and turkey herpesvirus infected lymphocytes. J Gen Virol. 1982; 63:333-341. https://dx.doi. org/10.1099/0022-1317-63-2-333

23. Calnek BW, Schat KA, Ross LJN, Shek WR, Chen CLH. Further characterization of Marek's disease virus infected lymphocytes. I. In vivo infection. Int J Cancer. 1984; 33:389-398. PMID: 6321364

24. Calnek BW, Schat KA, Ross LJN, Chen CLH. Further characterization of Marek's disease virus infected lymphocytes. II. In vitro infection. Int J Cancer. 1984; 33:399-406. PMID: $\underline{6321365}$ 
25. Davidson I, Borenshtain R. Novel applications of feather tip extracts from MDV-infected chickens; diagnosis of commercial broilers, whole genome separation by PFGE and synchronic mucosal infection FEMS. Immunol Med Microbiol. 2003; 38:199-203. DOI: https://doi.org/10.1016/S0928$\underline{8244(03) 00177-9}$

26. Davidson I, Artzi N, Shkoda I, Lublin A, Loeb $E$, Schat KA. The contribution of feathers in the spread of chicken anemia virus. Virus Res. 2008; 132(1-2):152-9. DOI: https://doi.org/10.1016/j. virusres.2007.11.012

27. Haq K, Schat KA, Sharif. S. Immunity to Marek's disease: Where are we now?. Dev Comp Immunol. 2013; 41:439-446. DOI: https://doi.org/10.1016/j. dci.2013.04.001

28. Omar AR, Schat KA. Syngeneic Marek's disease virus (MDV)-specific cell-mediated immune responses against immediate early, late, and unique MDV proteins. Virology. 1996; 222:87-99. https:// doi.org/10.1006/viro.1996.0400 PMID: $\underline{806490}$

29. Sharma JM, Witter RL. The effect of B-cell immunosuppression on age-related resistance of chickens to Marek's disease. Cancer Res. 1975. 35:711-717. PMID: 234791

30. Parvizi P, Abdul-Careem MF, K. Haq N, ThanthrigeDon, Schat KA. Immune responses against Marek's disease virus. Animal Health Research Reviews. 2010; 11(2):123-134. DOI: https://doi. org/10.1017/S1466252310000022

31. Becker $Y$, Asher $Y$, Tabor $E$, Davidson I, Malkinson $M$, Weisman $Y$. Polymerase chain reaction for differentiation between pathogenic and nonpathogenic serotype 1 Marek's disease viruses (MDV) and vaccine viruses of MDV-serotypes 2 and 3. J Virol Methods. 1992; 40(3):307-22. PMID: 1335457

32. Wei X, Shi X, Zhao Y, Zhang J, Wang M, Liu C, et al. Development of a rapid and specific loop-mediated isothermal amplification detection method that targets Marek's disease virus meq gene. J Virol Methods. 2012; 183(2):196-200. DOI: https:// doi.org/10.1016/j.jviromet.2012.04.014

33. Davidson I, Borenshtain R, Weisman Y. Molecular identification of the Marek's disease virus vaccine strain CVI988 in vaccinated chickens. J Vet Med B Infect Dis Vet Public Health. 2002; 49(2):83-87. PMID: 12002424

34. Baigent SJ, Petherbridge LJ, Howes K, Smith LP, Currie RJW, Nair VK. Absolute quantitation of Marek's disease virus genome copy number in chicken feather and lymphocyte samples using real-time PCR. J Virol Methods. 2005; 123(1):53-64. DOI: https://doi.org/10.1016/j. jviromet.2004.08.019

35. Islam A, Cheetham BF, Mahony TJ, Young PL, Walkden-Brown SW. Absolute quantitation of Marek's disease virus and Herpesvirus of turkeys in chicken lymphocyte, feather tip and dust samples using real-time PCR. J Virol Methods. 2006; 132(1-2):127-34. DOI: https://doi.org/10.1016/j. jviromet.2005.10.009
36. Levy $H$, Maray $T$, Davidson $I$, Malkinson $M$, Becker Y, Maray T, et al. Replication of Marek' $s$ disease virus in chicken feather tips containing vaccinal turkey herpesvirus DNA Replication of Marek' s disease virus in chicken feather tips containing vaccinal turkey herpesvirus DNA. Avian Pathol. 2007; 20(1):35-44.DOI: https://doi. org/10.1080/03079459108418739

37. Baigent SJ, Smith LP, Petherbridge LJ, Nair VK. Differential quantification of cloned CVI988 vaccine strain and virulent RB-1B strain of Marek's disease viruses in chicken tissues, using real-time PCR. Res Vet Sci. 2011; 91(1):167-74. DOI: https:// doi.org/10.1016/j.rvsc.2010.08.002

38. Islam T, Walkden-brown SW, Renz KG, Islam AFMF, Ralapanawe S. Replication kinetics and shedding of very virulent Marek' s disease virus and vaccinal Rispens / CVI988 virus during single and mixed infections varying in order and interval between infections. Vet Microbiol. 2014; 173(3-4):208-23. http://dx.doi.org/10.1016/j.vetmic.2014.07.027

39. Walkden-Brown SW, Islam A, Islam A, Burgess SK, Groves PJ, Cooke J. Pathotyping of Australian isolates of Marek's disease virus in commercial broiler chickens vaccinated with herpesvirus of turkeys (HVT) or bivalent (HVT/SB1) vaccine and association with viral load in the spleen and feather dander. Aust Vet J. 2013; 91(8):341-50. http:// dx.doi.org/10.1111/avj.12084

40. Witter RL, Calnek BW, Buscaglia C, Gimeno IM, Schat KA. Classification of Marek's disease viruses according to pathotype: philosophy and methodology. Avian Pathol. 2005; 34:75-90. DOI: https://doi.org/10.1080/03079450500059255

41. Witter RL. Increased Virulence of Marek' s Disease Virus Field Isolates. Avian Dis. 1997; 41(1):149-63. PMID: 9087332

42. Dudnikova E, Norkina S, Vlasov A, Slobodchuk A Lee LF, Witter RL. Evaluation of Marek's disease field isolates by the "best fit" pathotyping assay. Avian Pathol; 2007; 36(2):135-43. http://dx.doi. org/10.1080/03079450701209857

43. Calnek BW, Harris RW, Buscaglia C, Schat KA, Lucio. B. Relationship between the immunosuppressive potential and the pathotype of Marek's disease virus isolates. Avian Dis. 1998; 42(1):124-132. PMID: 9533089

44. Zhang Y, Li Z, Bao K, Lv H, Gao Y, Gao H, et al. Pathogenic characteristics of Marek's disease virus field strains prevalent in China and the effectiveness of existing vaccines against them. Vet Microbiol. 2015; 177(1-2):62-8. DOI: https://doi. org/10.1016/j.vetmic.2014.12.020

45. Renz KG, Islam A, Cheetham BF, Walkden-Brown SW. Absolute quantification using real-time polymerase chain reaction of Marek's disease virus serotype 2 in field dust samples, feather tips and spleens. J Virol Methods. 2006; 135(2):186-91. DOI: https:// doi.org/10.1016/j.jviromet.2006.03.017 
46. Haridy M, Goryo M, Sasaki J, Okada K. Pathological and immunohistochemical study of chickens with co-infection of Marek's disease virus and chicken anaemia virus,. Avian Pathol. 2009; 38(6):469-83. DOI: https://doi.org/10.1080/03079450903349162

47. Xiu-guo D, Guo Z, Zi-qiang C, Gui-hua W, Xiangkai $M$, Ting-ting $G$, et al. Dynamic Pathology and Antigen Location Study on Broiler Breeders with Coinfection of Marek's Disease Virus and Reticuloendotheliosis Virus. Agric Sci China. 2008; 7(11):1387-93. DOI: https://doi.org/10.1016/ $\underline{\mathrm{S} 1671-2927(08) 60189-3}$

48. Baigent SJ, Smith LP, Nair VK, Currie RJW. Vaccinal control of Marek's disease: current challenges, and future strategies to maximize protection. Vet Immunol Immunopathol. 2006; 112(1-2):78-86. DOI: https://doi.org/10.1016/j. vetimm.2006.03.014

49. Ralapanawe S. Field studies on the detection, persistence and spread of the Rispens CVI988 vaccine virus and the extent of co- infection with Marek' s disease virus. Aust Vet J. 2016; 94(9):329-37. doi: https://doi.org/10.1111/ avj.12479
50. Davison F, Nair V. Marek's Disease: An evolving Problem. 1st ed.. Compton, UK: Elsevier B.V.; 2004.

51. López S, Piedrahita D, Ramírez GC, Aranzazu D, Williams S, Chaparro J. La inmunodepresión subclínica, un problema importante en los sistemas de producción avícola. Plumazos. 2015; (51):1423. URL Available in: http://pubhtml5.com/fcla/ ohnv/basic

52. Osterrieder N, Kamil JP, Schumacher D, Tischer BK, Trapp S. Marek's disease virus: from miasma to model. Nat Rev Microbiol. 2006; 4:283-294. DOI: https://doi.org/10.1038/nrmicro1382

53. Lopera Toro PA. Evaluación epidemiológica molecular de las cepas circulantes del virus de la enfermedad de Marek en brotes presentados en Colombia durante el período de 2000 al 2012. [Tesis de Doctorado en Ciencias Animales]. Colombia: Universidad de Antioquia; 2017. 